\title{
Estimating Value Added Tax Gap in Turkey
}

\author{
Ebru Canıkalp ${ }^{1}$, İlter Ünlükaplan², Muhammed Çelik ${ }^{3}$ \\ ${ }^{1,2}$ Cukurova University, Turkey \\ ${ }^{3}$ Uludağ University, Turkey
}

\begin{abstract}
As an important issue in the fiscal structure of a country, tax gap is defined as the difference between tax burden that the taxpayer should face and the amount actually paid. In this study, tax gap was evaluated by the framework of the Value Added Tax. The reason behind this choice, i.e. Value Added Tax Gap (VAT Gap) is to make an effort to evaluate the efficiency of the tax administration, the compliance of the taxpayers and the relationship between policy gap and the compliance gap. With this aim, VAT Gap and the various methods to calculate this gapwere examined. Furthermore, based on the reports by the European Commission, VAT Gap in Turkey for 1993-2014 period were estimated and evaluated by employing thetopdown method.
\end{abstract}

Keywords: Compliance Gap, Policy Gap, VAT Gap

\section{INTRODUCTION}

The tax gap is defined as the difference between potential collectable tax revenue, and the amount of that is actually collected. On a theoretical base, the state of negligence at collecting taxes, errors made in determining the tax base, tax avoidance and tax evasion, incomplete statements, tax allowances and exemptions constitute the factors behind the tax gap. Several studies aimed to explain the factors determining the magnitude of the tax gap. Plumpley (2005) examines incomplete statements, Giles (1999) focuses on informal economy and Reckon (2009) investigates tax allowances, exemptions and tax expenditures to explain the tax gap.

Although the tax gap concept is a common and popular subject either in academics or the public finance administration process, many studies and researches are being conducted. "Her Majesty's Revenue and Customs" (HMRC) and Thackray (2012) have been making estimations for the VAT tax gap in the United Kingdom. Australian Taxation Office pursues regular tax gap estimation in Australian Economy. Several governmental institutions, Ministries of Finance and European Commission estimate tax gap for the European Union countries. IMF regularly estimates tax gap for the Southern African countries. In Turkey, many arguments that support the prediction that tax evasion leads to increasing tax gap have been powered. The motivations behind this study are that the tax evasion is not a sufficient indicator to explain tax gap and the lack of such estimations by governmental institutions in Turkey.

VAT tax gap has a big importance to assess informal economy, tax consciousness of citizens and tax morale. Recently, many studies have been taking place in the public finance literature devoted to measuring the efficiency of the VAT. Measuring revenue ratio of VAT does not indicate a perfect compliance in taxation. Contrariwise, combining this ratio with a measure called political productivity and compliance productivity leads to estimating tax gap precisely. According to this calculations, tax gap rises as the tax morale and tax consciousness are relatively low. In addition, tax cuts in the VAT rates, tax exemptions and active reactions initiated from psychological reasons increase the gap between real and potential tax revenue. Revenue ratio of VAT and other indicators can be estimated by compliance gap and policy gap (CSERCB, 2013, p. 20). 


\author{
Ebru Canıkalp, İlter Ünlükaplan, Muhammed Çelik \\ Estimating Value Added Tax Gap in Turkey
}

In this study, we will focus on VAT Tax Gap, defined as the difference between accrued amount of the VAT Tax revenue and the amount that the taxpayer should pay on a theoretical basis (Zidkova, 2014, p.514). Within this framework, the main object of this paper is to calculate VAT tax gap in Turkey by decomposing into compliance gap and policy gap. The paper is organized as follows: Section 2 is devoted to explainingthe compliance gap and policy gap. Section 3 gives an overview of methods to calculate tax gap; Section 4 includes revenue performance of VAT and VAT gap in Turkey for 19932014 Period. Section 5 concludes.

\title{
2. COMPLIANCE GAP AND POLICY GAP
}

Compliance gap is stated as the difference between the amount that the taxpayer should pay on an ideal basis and the actual tax payment, caused by the taxpayer's application to tax loopholes or tax evasion with illegal ways. Tax evasion and incomplete statements, known as "lost economy", leads to collecting tax revenue under the amount envisaged in the law and leads to the tax gap.

Thackray and Ueda (2014, p.13), examine compliance gap under two different concepts: Allocation gap and base tax gap. Allocation gap is gauged by audits, investigation of base taxgap, VAT tax base, and VAT tax refund. Instead of using the uncollected amount of tax, allocationgapis calculated by comparing potential tax payments with atotal value of tax revenue. Tax base gap, also labeled as "unexplained gap" in the literature, is defined as the difference between total compliance gap and allocation gap.

Policy gap is defined as the gap in the tax collections, generated by the differentiation of VAT rate among different countries. Keen (2013, p. 3), decompose policy gap into two different gap concepts: Rate differentiation and exemptions. Imposing lower VAT tax rates than the standard VAT rate or zero tax rate for the essential goods and services indicate rate differentiation while exempting specified people from taxation constitutes exemption gap.

Rate differentiation causes several political decisions like tax exemptions and allowances. It also generates a certain situation in which taxpayers faces with tax evasion and avoidance, thereby causing a gap in tax collection. As shown by equation 1 , it indicates a difference between potential and actual VAT collections, namely compliance gap. Compliance gap is expressed as a percent of VAT collections or GDP (CSERCB 2013, p. 21).

\section{VAT Compliance Gap: (Potential Collectible VAT - VAT Collections) / VAT Collections (1)}

After measuring compliance gap, policy gap is derived by certain steps. Policy gap is the VAT ratio payments without exemptions, allowances and reduced rates to actual VAT collections. Equation 2 summarizes this calculation process (CSERCB, 2013, s. 35):

\section{Policy Gap: (VAT Collections- VAT Compliance Gap) / (1- VAT Compliance GAP) (2)}

Agha and Houghton (1996) aimed to analyze the relationship between compliance gap and policy gap. They focused on three hypotheses and reached following results:

1. Higher VAT rate can be associated with low level of VAT compliance

2. High VAT rate has negative effects on the level of VAT compliance

3. Increasing VAT compliance is linked with legislation be in force for a long time.

Moreover, countries with lower population are expected to have a high level of VAT compliance. Keen and Smith (2007, p. 11) examined the relationship between these two decomposed gaps for the highlevel income countries. In their studies, high VAT rate causes tax fraud and evasion as it encourages informal activities. In case of rate differentiation in VAT, taxpayers consider the reduced tax rate and look for the ways for the tax fraud and evasion. They also stress that tax exemption and allowances used for overcoming the technical problems for allocating and using tax as a fiscal tool and can be defined as efficient tools for preventing tax fraud and evasion. 
As inferred from equation 1 and 2, compliance gap and the policy gap are not independent of each other. The relationship between these two gap definitions is obvious. Tax exemptions, allowances, reductions in tax rate and tax threshold are the factors that contribute to policy gap in a positive manner. The increase in policy gap, arising from legal arrangements, causes a decrease in compliance gap. Tax exemptions and deductions discourage taxpayer for tax exemptions and tax frauds and finally foster them to reach tax compliance level. On the other hand, this approach may cause taxpayers to examine the loopholes in the tax system thereby giving rise to policy gap.

\section{METHODS TO CALCULATE TAX GAP}

Almost in all economies, taxation has two important dimensions. It is considered to be a fiscal burden on the taxpayers as well as causing to the emergence of the tax compliance problems. Although the effects of the frequency of the tax amnesty conducted in the country, not to treat taxes as aliability, corruption in tax morale and the political decisions are well known, the magnitude of these effect has to be questioned. This situation generates some questions like "Does the tax administration working effectively?", "What is the contribution of fiscal policy to tax revenue?", "What is the level of tax compliance and tax morale of the taxpayers?". As a reply to these questions, a comparison, including the calculation of VAT tax revenue, compliance gap, and policy gap, should be made. In the literature, two basic approaches are known for calculating tax gap: "top-down method" based macroeconomic data and "bottom-up method" based on microeconomic data.

\subsection{Top-Down method}

As a method to calculate tax gap, top-down approach employs macroeconomic methods. The top-down approach is based on a theoretical calculation of the tax base used to estimate the tax liability. By ensuring compliance with the essence of the law and provided documents theoreticalliabilities are taken from all individuals (IFPTMFSR 2012, p. 3). The top-down approach is also known as "Indirect method" as it utilizes tax return records and data other than the connections. According to the topdown approach, tax gap is the difference between the theoretical tax liabilities and the total tax revenue. As mentioned before, the cause of this difference is examinedunder the two main groups of compliance gap and the policy gap.

\section{ACGD $=$ Potential Collections}

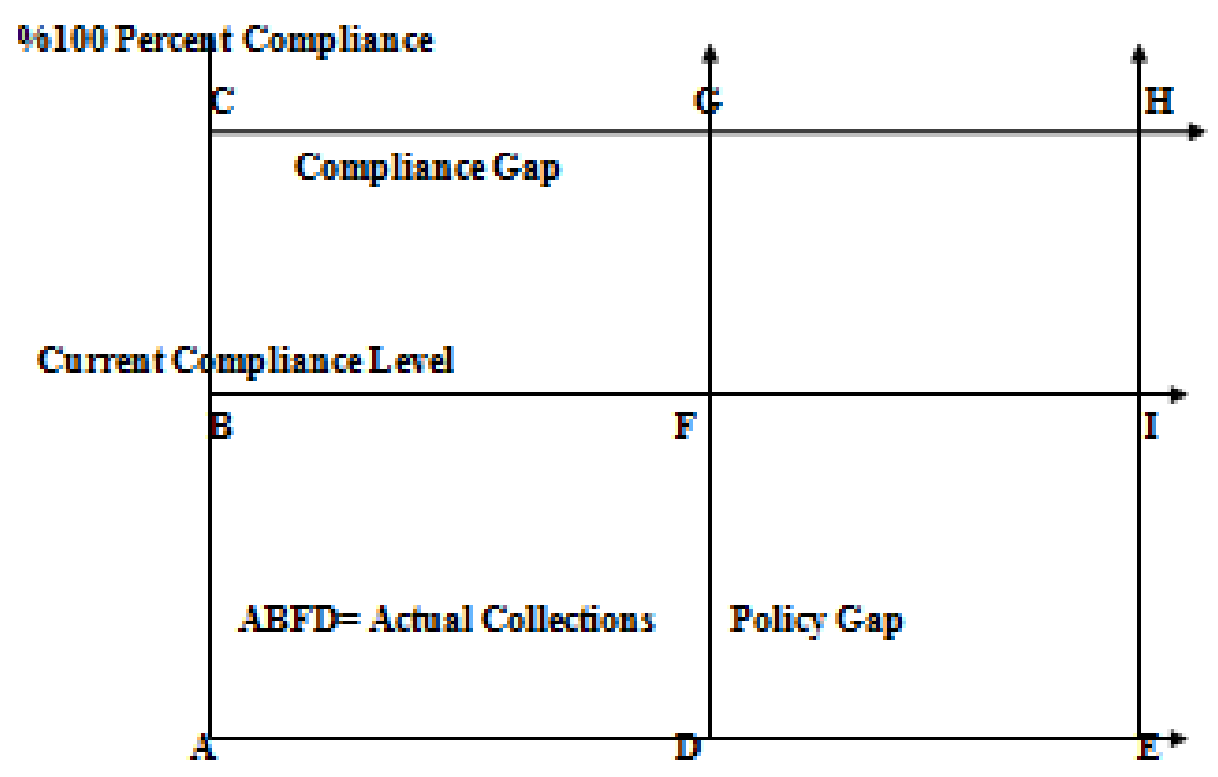

Current Policy Structure

Normative Policy Structure

Figure1: Calculating Tax Gap (Presentation Hutton from Fiscalis Tax Gap Project Group) 
Within the framework of the top-down approach, potential collectable VAT revenue, and collected VAT revenue are compared. Then, based on national income accounts and other statistical resources, several computations are made. As shown in figure 1, ACDG stands for potential collectable VAT revenue and ABFD for the collected VAT revenue. If one subtracts the collected VAT revenue (ABFD) from the potential collectable VAT revenue (ACDG), compliance gap is found (ACDG-ABFD). With the top-down approach, policy gapis calculated in three steps. First, the ratio of the collected VAT revenue (ABFD) to potential collectable VAT revenue (ACGD) is calculated. Then, ACGD area, the sum of collected VAT revenue and compliance gap (ACGD) is subtracted from thefull potential area (ACHE). The final step includes multiplying the ratio calculated in step 1 with the difference obtained in step 2 (DFIE) (Presentation Hutton from Fiscalis Tax Gap Project Group, p.16-17).

To conduct an effective analysis of the tax gap, Toro et al. (2013) discourse five canons: Collection of thetax base from independent sources, theaccuracy of the statistical data, being consistency and comprehensive and detailed data. The disadvantage of the top-down method, which is based on macroeconomic foundations, is arisen from the fact that it does not assure household or firm's tax gap at themicroeconomic level when reaching to thetotal tax gap. Accordingly, when examining tax gap choice between micro or macro level is a crucial selection (IFPTMFSR, 2012).

\subsection{Bottom-Up Method}

An alternative method to calculate tax gap is "bottom up" approach. This method reaches to "taxable income", while the top-down method does not. However, it is longer and more comprehensive than the top-down method. In this approach, tax gap is calculated by households and firms' microdata. Within this method, gathered results are applied to all taxpayer groups, the population of a country and firms with the same characteristics (IFPTMFSR, 2012, p. 10). In other words, with the bottom-up approach, total tax gap is calculated from the tax gap components. The most commonly used components in the microeconomic approach are the data matching, risk analysis, and the stochastic researches. (Thackray, 2012, p. 12).

- Data matching: Controlling the information and data from different resources for the determination of undeclared assets and income.

- Risk analysis: The analysis of the big businesses' potential losses stems from tax risk and tax avoidance by the tax experts.

- Stochastic researches: Evaluating the results derived from the controlling the information obtained from the randomly selected assessments.

Bottom-up approach, as in the top-down method, ensures only an indefinite estimate of the total tax gap while it has some important advantages comprising functional and beneficial information. Detailed tax gap analysis, requisite for the bottom-up approach, provides prioritization of compliance resources to maximize collected tax revenue.(Rubin, 2011, p. 111). Bottom-up approach provides more information of tax gap than the top down method. As the operational information is weakened as a result of deterioration in the tax governance, nearly all countries use prepared information and causing the top down method to give more accurate information. (Keen, 2013, p. 18). Therefore, it can be said that bottom-up approach is a rough estimation of underreported income. Because, bad governance quality generates doubt of the accuracy, consistency, and independence of the obtained data and obstructs to reach clear information on tax gap.

\section{REVENUE PERFORMANCE OF VAT AND VAT GAP IN TURKEY FOR 1993-2014 PERIOD}

In this part of the study, VAT gap, policy gap and compliance gap in Turkey were calculated by using top-downbased on macroeconomicapproachmethod for the1993-2014period. The reason behind this 
selection is the ease of collecting data on tax liability and tax revenue in Turkey. Also, Turkey, as a country with a low level of quality of governance, as the bottom-up method arouses suspicion about firms' underreported earnings and informaldata; thisapproachwas not preferred. Used data in this study, VAT revenue and VAT rate from OECD Tax Revenue Statistics, GDP and consumer spending from Annual National Accounts, accrued tax and collected tax from Turkish Revenue Administration are taken.

Table 1: VAT Revenue Performance Indicators and Tax Gap Data in Turkey (1993-2014) (Authors' Calculations)

\begin{tabular}{|llll|}
\hline Years & Compliance Gap/VTTL & Compliance Gap/GDP & Policy Gap \\
\hline $\mathbf{1 9 9 3}$ & 0,26 & 0,008 & 0,48 \\
\hline $\mathbf{1 9 9 4}$ & 0,27 & 0,009 & 0,55 \\
\hline $\mathbf{1 9 9 5}$ & 0,28 & 0,010 & 0,37 \\
\hline $\mathbf{1 9 9 6}$ & 0,28 & 0,011 & 0,43 \\
\hline $\mathbf{1 9 9 7}$ & 0,27 & 0,011 & 0,45 \\
\hline $\mathbf{1 9 9 8}$ & 0,28 & 0,011 & 0,42 \\
\hline $\mathbf{1 9 9 9}$ & 0,31 & 0,012 & 0,40 \\
\hline $\mathbf{2 0 0 0}$ & 0,29 & 0,014 & 0,44 \\
\hline $\mathbf{2 0 0 1}$ & 0,31 & 0,016 & 0,44 \\
\hline $\mathbf{2 0 0 2}$ & 0,20 & 0,012 & 0,48 \\
\hline $\mathbf{2 0 0 3}$ & 0,17 & 0,010 & 0,46 \\
\hline $\mathbf{2 0 0 4}$ & 0,16 & 0,010 & 0,39 \\
\hline $\mathbf{2 0 0 5}$ & 0,19 & 0,011 & 0,37 \\
\hline $\mathbf{2 0 0 6}$ & 0,08 & 0,005 & 0,39 \\
\hline $\mathbf{2 0 0 7}$ & 0,10 & 0,007 & 0,36 \\
\hline $\mathbf{2 0 0 8}$ & 0,11 & 0,007 & 0,35 \\
\hline $\mathbf{2 0 0 9}$ & 0,14 & 0,009 & 0,33 \\
\hline $\mathbf{2 0 1 0}$ & 0,16 & 0,011 & 0,39 \\
\hline $\mathbf{2 0 1 1}$ & 0,18 & 0,013 & 0,42 \\
\hline $\mathbf{2 0 1 2}$ & 0,17 & 0,012 & 0,40 \\
\hline $\mathbf{2 0 1 3}$ & 0,17 & 0,013 & 0,44 \\
\hline $\mathbf{2 0 1 4}$ & 0,20 & 0,015 & 0,41 \\
\hline & & 0 & 0,0 \\
\hline
\end{tabular}

Figure 2, visualizes the Table 1's calculations of compliance gap and policy gap in Turkey. In the figure, it is observed that policy gap is greater than the compliance gap in all periods. Within this framework, it is possible to state that forgone tax collections resulted from exemptions, deductions and rate differentiations are greater than the loss caused by the informal economy.

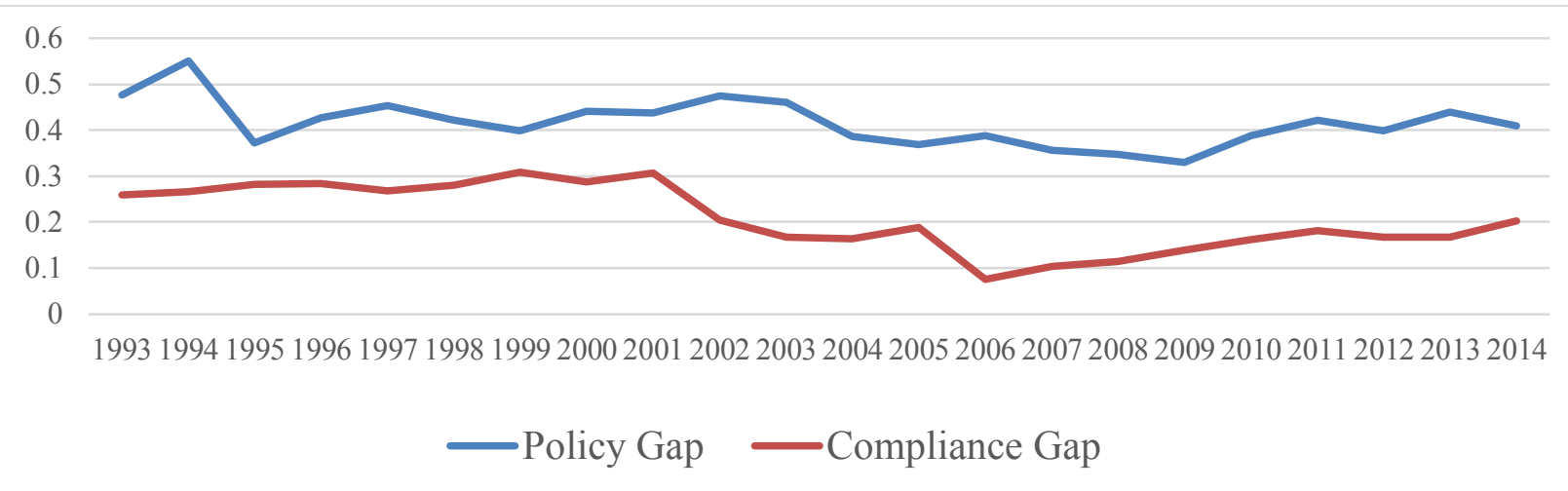

Figure 2: Policy Gap and Compliance Gap in Turkey (1993-2014) 


\section{Ebru Canıkalp, İter Ünlükaplan, Muhammed Çelik \\ Estimating Value Added Tax Gap in Turkey}

In 1995 , VAT rate in Turkey was increased from $10 \%$ to $15 \%$, causing a fall in the policy gap. Despite that, increasing VAT rate to $17 \%$ caused a rise in policy gap. This situation can be linked to tax refund with the Law No. 4369 in 2000, exceeding the specified amount to taxpayers, in the case of the delivery and discharge of goods and services with reduced tax rate. This decision can be said to have an effect on the increase of the policy gap. The introduction of the Special Consumption Tax In 2002, abolishing $26 \%$ and $40 \%$ tax rates and assigning $18 \%$ the standard rate and conducting reduced VAT rate system caused an increase in policy gap.

The frequency of the tax amnesties in Turkey causes policy gap as well as compliance gap for the taxpayers. Since 2003, four tax amnesties have been observed. Moreover, taxpayers' expectations of tax amnesties cause an increase in tax gap. By examining previous tax amnesties, the elimination of tax penalties and late fees have been on duty, leaving tax base unchanged. Nevertheless, the main reason for the formation of the tax gap is taxpayers' expectations for recurrent tax amnesties and the perception of the taxpayer in which he will have benefit from the tax deductions, thereby causing corruption in tax morale.

To our knowledge, in Turkey, Ministry of Finance, Treasury Undersecretary, and other associated institutions have not conducted statistical analyses for tax gap. The lack of these studies can be regarded as the justification of policy gap and compliance gap in Turkey. In addition to taxpayers' compliance, compliance gap indicates the performance of the tax administration. The absence of the tax gap calculations causes the disappearance of the deterrent effect on taxpayers and prevents laying out the operating performance in the tax offices. As in other countries, calculation of tax gap by governmental institutions and decomposing tax gap into policy gap and compliance gap will improve tax gap as well as the efficiency of the tax administration and will contribute to the significance of the policies to be followed within this framework.

Considering the sum of compliance and the policy gap in Turkey, Table 1 indicates that this value ranges between $46 \%$ and $75 \%$. Based on the tax gap data, Silvani and Bear (1997) divide the countries into four categories ${ }^{1}$. In accordance with calculations, Turkey finds itself in the group of "countries with inefficient tax policy".In this study, countries in this group face with the lack of financial resources, qualified and trained personnel, processes that reduce efficiency, absence of the deterrent mechanisms preventing compliance gap, lack of efficient taxpayer service, inefficiency of the tax administration, the weakness of the tax administration in tax collecting and the problem of corruption.Calculations in our study support the foresight that these problems exist in Turkey.

Efficient execution of the VAT requires a unique, standard rate implication. Exact measurement of the VAT performance is not an easy job. Consequently, the term of "performance" should be stated clearly and VAT gap should entirely be scoped out. Considering the essence of VAT, OECD (2008) defines this tax as a broad-based and flat tax. It is also statedthat VAT is neither a redistributive nor a tax with social purposes. That's why exceptions and exemptions are out of the VAT's scope (OECD, 2008, p. 66). In this wise, fiscal function of the VAT, ensuring the correspondence between tax administration and taxpayers has been pointed out for the sake of to implement VAT flat rate. Considering the redistributive function of the government and modern taxation principles, implementing a VAT flat rate is not an easy job.

\section{VAT Revenue Ratio = VAT Revenue /(Consumption- VAT Revenue) * VAT Rate (3)}

As stated by equation 1, VAT Revenue Ratio ranges from 0 to 1 . As it approaches to 1 , VAT is said be collected in an efficient manner and there is a perfect correspondence between tax administration and taxpayers, while 0 denotes negative situation policy gap and compliance gap (Çelikkaya, 2011, p. 117). Figure 3 exhibits VAT Revenue Ratio in Turkey for 1993-2014.

\footnotetext{
1 1.group: Tax gap is $\leq 10 \%$, countries with efficient tax administration

2. group: Tax gap is $\geq 10 \%, \leq 20 \%$ countries with partially efficient tax administration

3. group: Tax gap is $\geq 20 \%, \leq 40 \%$, countries with partially inefficient tax administration

4.group: Tax gap is $\geq 40 \%$, countries with inefficient tax administration
} 


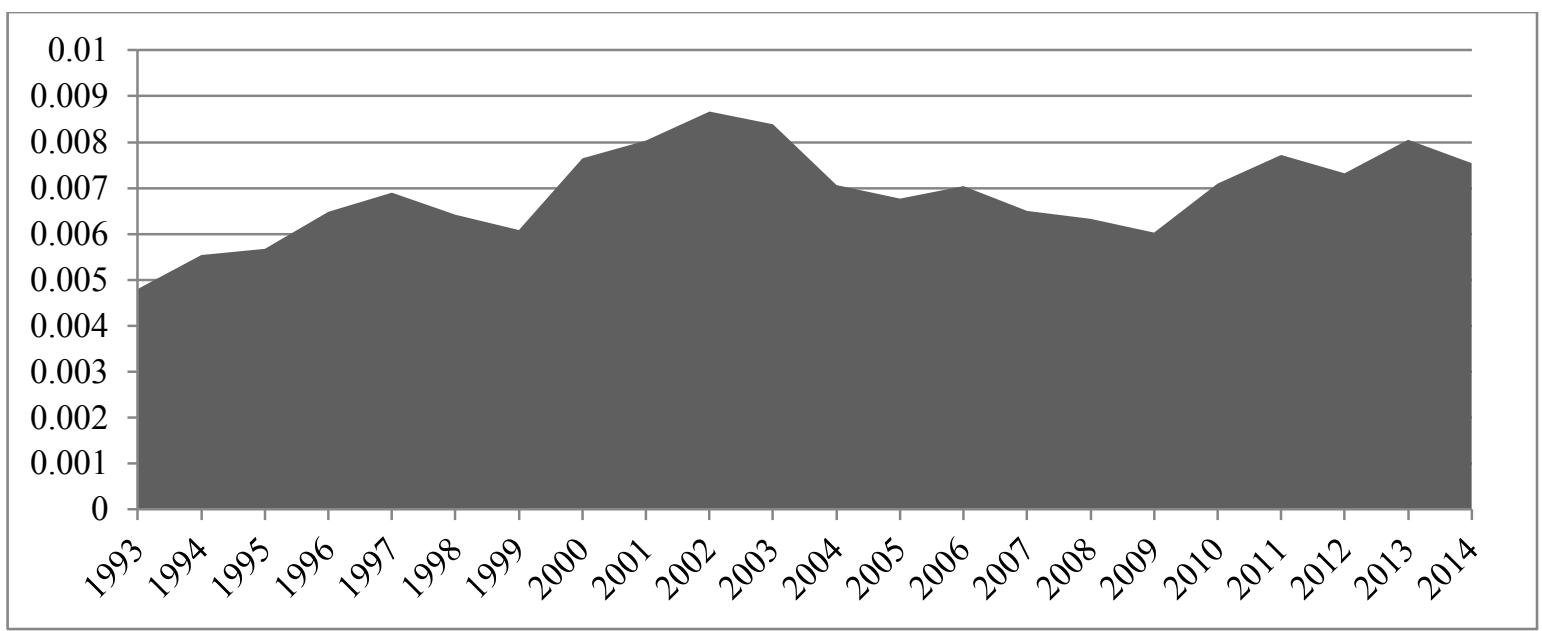

Figure 3: VAT Revenue Ratio in Turkey (1993-2014) (Authors' Calculations)

VAT Revenue Ratio in Turkey ranges from 0,004 and 0,009. These values can be attributed to the excess value of the base gap, as a component of the compliance gap, affecting from the high level of the tax exemptions, deductions, and tax evasion.

\section{CONCLUDING REMARKS}

Firstly, VAT gap which gains importance recently in the literature should be calculated by various governmental institutions to avoid VAT gap. After that, the cause of gap should be determined and search for solutions.

One of the important steps to reduce VAT gap is a legal legitimate which has been in force for a long time and avoid frequent changes in legislation. Without rate difference, clear and understandable legislation for VAT is crucial for taxpayers and tax administration to reduce taxpayer's compliance costs.

To ensure voluntary compliance for VAT, the frequency of expected tax amnesties should be adjusted so as to reduce the compliance gap. Investigating psychology of taxpayer and tax consciousness can be treated as effective policies against compliance gap.

In political approach, politicians see the individual as a vote. To maximize vote, politicians use exemptions as deductions as political tools. This situation creates policy gap, and it can be solved by efficient reform of the tax system. Gemmel and Hasseldine (2012) expressed that, the measure to be taken improves the tax system influence consumption pattern, and it can affect policy gap directly or indirectly, so it provides processing of the control mechanism.

Electronic billing and simplification of VAT procedures for small business increase the compliance for VAT. However, tax penalties should persuade taxpayers who fraud document, do not pay VAT and seek ways to tax evasion.

\section{REFERENCES}

- Agha, A. and Haughton, J. (1996),"Designing VAT Systems: Some Efficiency Considerations", Review of Economics and Statistics, 303-308.

- Center for Social and Economic Research and Central Planning Bureau.- CSERCPB (2013),Study to quantify and analyse the VAT Gap in the EU-27 Member States. Warsaw: European Commission, TAXUD. 
- Çelikkaya, A.,(2011),"Examining the Structural Evaluation of VAT and Its Last Harmonization Efforts in OECD Countries", Sosyo Ekonomi. 14(14), 111-126.

- Fiscalis Tax Gap Project Group (2016), The Concept of Tax Gaps Report on VAT Gap Estimations. (FPG/041), Brussels, March.

- Gemmell, N., and Hasseldine, J., (2012), "The Tax Gap: A Methodological Review", Working Paper Series 2435,Victoria University of Wellington, Chair in Public Finance.

- Giles, D. E. (1999), "Measuring the Hidden Economy: Implications for Econometric Modelling", The Economic Journal, 109/456, 370-380.

- Institute for Financial Policy The Ministry of Finance of the Slovak Republic -IFPTMFSR (2012), The Estimate of the Value Added Tax Revenue Loss, Slovak Republic.

- Keen, M. (2013), "The Anatomy of the VAT",IMF Working Paper, WP/13/111. IMF.

- Keen, M., and Smith, S. (2007). VAT Fraud and Evasion: What Do We Know, and What Can be Done?. IMF Working Paper, WP/07/31. IMF.

- OECD (2008), Consumption Tax Trends.

- OECD Annual National Accounts Website (2015), available at:http://stats.oecd.org/Index.aspx?DataSetCode=SNA TABLE1 (accessed 10.10.2015).

- OECD Tax Revenue Statistics Website (2015), available at:http://stats.oecd.org/index.aspx?DataSetCode=REV (accessed 10.10.2015).

- Plumley, A. (2005), "Preliminary Update of the Tax Year 2001 Individual Income Tax Underreporting Gap Estimates", inRecent Research on Tax Administration and Compliance: Proceedings of the 2005 IRS Research Conference, Statistics of Income, Internal Revenue Service, 15-25.

- Reckon. (2009), Study to Quantify and Analyse the VAT Gap in the EU-25 Member States, London: DG Taxation and Customs Union.

- Rubin, M. (2011),"The Practicality of the Top-Down Approach To Estimating the Direct Tax Gap",Her Majesty's Revenue and Customs , 109-127.

- Silvani, C., and Baer, K. (1997), "Designing a Tax Administration Reform Strategy: Experiences and Guidelines", Washington D.C.: IMF Fiscal Affairs Department. WP/97/30

- Thackray, M. (2012), The UK Tax Gap. HM Revenue \& Customs, January.

- Thackray, M., and Ueda J. (2014), "Report of The Findings From The Revenue Administration Gap Analysis Program - The Value-Added Tax Gap In Estonia",IMF, Report No. 14/133.

- Toro, J., Ogata, K., Hutton, E., and Caner, S. (2013), "Assesment of HMRC's Tax Gap Analysis", IMF, Fiscal Affairs Department, Country Report No. 13/314.

- Turkish Revenue Administration Website (2015), available at:http://www.gib.gov.tr/fileadmin/user upload/VI/GBG1.html (accessed 10.10.2015).

- Zidkova, H., (2014), "Determinants of Vat Gap In EU", Prague Economic Papers, 4, s.514-530. 